\title{
A computerized system for recording and analysis of self-observations of couples' interaction
}

\author{
HOWARD J. MARKMAN and STEVEN E. POLTROCK \\ University of Denver, Denver, Colorado 80208
}

This paper describes a method for recording couples' observations of their communications during an ongoing interaction sequence. The procedure allows the recording and decoding of immediate reactions, while maintaining an ecologically valid observation environment. Responses are encoded on a stereo cassette tape player and are decoded by a PDP-11/10 computer with two Schmitt triggers that count the peaks in the tones. The computer provides analysis of the response value and time. Applications for other research problems in the areas of social and applied clinical psychology are discussed.

A variety of systems are currently available for recording, storing, and analyzing observational data from animal or human social interactions (e.g., Sidowski, 1977; Smith \& Begeman, 1980; Stephenson \& Roberts, 1977; Torgerson, 1977). These systems have in common several positive and negative attributes. Positive features include automated data recording and analysis, relative compactness, and portability. Negative features include high cost (e.g., $\$ 250-\$ 5,000$ ) and restricted range of usefulness. These systems are recommended for research situations calling for observers to code ongoing interaction. However, the researcher who is interested in capturing interactants' observations of their own interactions, as opposed to outside observers' reactions, will find that the above systems have limited applicability. The current paper describes a method for recording and decoding couples' observations of their communications during an ongoing sequence, while maintaining an ecologically valid observation environment.

\section{THE RESEARCH PROBLEM}

Recently, major advances have been made in understanding the role of marital interaction and communication in the development and maintenance of marital and family distress (Markman, Floyd, \& DicksonMarkman, in press; Weiss, 1980). Many conceptual frameworks have influenced the research in this area, including social exchange theory (Gottman, Notarius, Markman, Bank, Yoppi, \& Rubin, 1976; Thibaut \& Kelley, 1959), social learning theory (Weiss, Hops, \&

The authors would like to acknowledge the contribution of Dan Maddox, who built the communication-box hardware, and thank Frank Floyd, who helped develop the communication-box procedure, and our reviewers, for their helpful comments. Requests for reprints should be sent to Howard J. Markman, Psychology Department, University of Denver, Denver, Colorado 80208 .
Patterson, 1973), behavioral reinforcement theory (Birchler, Weiss, \& Vincent, 1975), and family systems theory (Birchler \& Spinks, 1980). Although these models use different languages, they have in common the prediction that the quality of the couples' interaction is a primary determinant of current and future marital and family satisfaction (or distress). The advances in this area have been made possible to a large degree by the development of observational coding systems that allow tests of the predictions concerning communication and marital satisfaction (Weiss, 1980). There are two types of coding systems: (1) those used by objective observers to evaluate the couples' interaction and (2) those used by the couples themselves to code their own interaction (see Markman, Notarius, Stephen, \& Smith, 1981, for a full review).

In the typical objective coding situation, observers code the couples' interactions either in vivo or while watching a videotape (e.g., Birchler et al., 1975). In the typical self-observation situation, couples provide ratings of their own interactions either in vivo or while watching a videotape of their interactions (e.g., Markman, 1979). Information from both the objective observer's perspective (i.e., outsiders) and the couple's own perspective (i.e., insiders) represents two distinct sources, and both are necessary for a comprehensive assessment of a couple's relationship (Olson, 1978).

An example of a research problem that calls for the use of couples' self-observations is provided by Markman, Jamieson, and Floyd (in press). We were testing a hypothesis derived by social exchange theory that the rewardingness of couples' premarital interaction will be predictive of their current and future level of relationship satisfaction. Since behavior exchange theory asserts that the reward value of interaction is determined by the interactants' reactions, as opposed to objective observers' reactions (Gottman et al., 1976), we needed a procedure that allowed couples to rate their reactions to each 
other's communication. We also wanted an automated system that allowed immediate data storage, retrieval, and analysis.

Automated data recording procedures (e.g., Datamyte; Smith \& Begeman, 1980) are currently readily available to allow objective observers to evaluate couples' interaction using any of the observational coding systems typically used by marital researchers. However, there are no automated procedures available for recording and analyzing self-observations (i.e., the couples' own ratings) of interaction. The computerized systems available for use by objective observers are not appropriate for use by couples for three reasons. The major reason is that the instrumentation required by automated methods is too large for couples to unobtrusively use while talking. Second, the process of entering coded data is too complex to allow immediate reactions of untrained subjects. Finally, these systems are very costly (e.g., $\$ 250-\$ 5,000)$. Thus, we needed a coding and recording system that met several criteria: (1) small (i.e., easily hand-held size), (2) ratings not available to partner, (3) recording of partner's data separately and sequentially for the purpose of subsequent analyses, (4) results immediately available, and (5) relatively inexpensive. A description follows of a procedure and necessary hardware and software that allow for the computerized recording and analysis of self-observations of couples.

\section{COMMUNICATION BOX PROCEDURE}

The communication box (Markman \& Floyd, 1980) is a $1 \times 2 \times 3$ in. plastic box with five buttons on it representing positive, very positive, neutral, negative, and very negative ratings. The box fits easily into the hand and is attached by a wire to a control box. The communication box is conceptually and procedurally similar to the "talk table" (Gottman et al., 1976; Markman, 1979), which is a mechanical device developed to measure the intent and impact of communication exchanges. The assessment procedure is conceptually grounded in social exchange theory (Thibaut \& Kelley, 1959), which predicts that an exchange of behaviors rated positively by interactants is an important determinant of the development and maintenance of successful relationships. The communication-box ratings are a measure of the perceived reward value of interaction, from the listener's perspective.

The experimental situation in which the procedure is used involves spouses' negotiating solutions to problem solving tasks. For example, they discuss the major problem area in their relationship. While they talk, the couples are instructed to use the communication box to rate each other's interaction. They are told that while discussing the communication tasks they will have to talk one at a time. A switch located in front of them controls a light that signals which partner has the "floor." The light is switched to the listener after the speaker has finished talking, signaling that a rating should be made. The couples are instructed to use the hand-held communication box to rate their partner's communication immediately after he/she finishes talking (i.e., when the floor switches). The speakers themselves determine when they are finished and signal this by switching the floor switch to their partner. The partner then rates his/her reactions, and the interaction proceeds. Couples are told to use the "positive" button when they feel positive or pleased by their partner's response and to use the "negative" button when they feel negative or displeased by what their partner said. The "neutral" button is used when the reaction is neither positive nor negative. Further, they are to push the "super positive" or "super negative" button to indicate very positive and very negative statements, respectively. The couples' conversations are videotaped and transcribed, so that the couples' own ratings eventually can be compared with objective coders' evaluations of the same units of interaction. The basic unit of analysis is one speaker's set of communications, which Raush, Barry, Hertel, and Swain (1974) refer to as a communication act.

Although the procedure may seem unnatural, couples learn to use the system quickly and report that they are comfortable using the boxes. We are currently conducting studies to determine potential differences between communication patterns using this procedure as compared with more naturalistic conditions.

The basic hardware and software issues are concerned with how to transform the buttonpresses into sequential data ready for analysis. The low data rates generated by subjects do not warrant use of a dedicated computer to collect and store the data. Furthermore, the unpredictable reliability of our university computer discourages its use as a timesharing data collection device. Therefore, an inexpensive system was developed to store encoded data on cassette tape for later analysis by a computer. This system has proved to be reliable, and it eliminates scheduling problems caused by competing demands for computer time.

\section{HARDWARE}

The five communication-box buttons each contain a contact closure that is connected to a Type 555 timer IC and operates as a multivibrator, as shown in Figure 1. The timer is located in a small control box attached to a coffee table. When subjects respond by pressing one of the five pushbuttons, the responses are encoded as tone

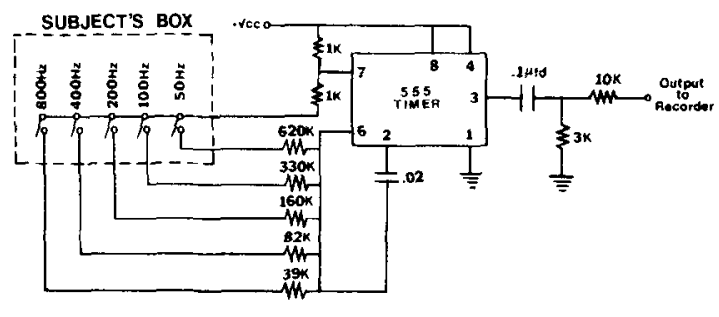

Figure 1. Schematic of the communication box and waveform generator. 
frequencies on one channel of a cassette tape in realtime. The tone frequency is selected by discharge resistors in series with the contact closures. The resistors and capacitor at the output of the timer IC serve as a voltage divider and shape the output to a waveform compatible with the audio recorder. Two identical circuits generate the tones for the two subjects. A single $6-\mathrm{V}$ power supply drives both generators.

When a subject provides a rating by pressing a button, the resulting tone is recorded by a Pioneer stereo cassette recorder. Each channel of the recorder is used to record the ratings of one member of the couple. The original sequence of ratings is reconstructed at a later time by playing these tapes with the recorder outputs connected to a computer.

The recorder outputs are connected to two Schmitt triggers that are part of the clock in a Lab Peripheral System on a PDP-11/10 computer. The Lab Peripheral System is no longer available, but equivalent Schmitt triggers are currently provided with the real-time clocks for Digital Equipment Corporation's PDP and LSI computers. Response time measurements are made with the line clock because the real-time clock cannot simultaneously provide Schmitt trigger inputs and time measurements.

\section{SOFTWARE}

The decoding and analysis of the recorded data are conducted by a combination of FORTRAN and MACRO routines available from the authors upon request. A MACRO routine called TRIGER provides the interface between FORTRAN and the Schmitt triggers. Flowcharts of TRIGER and its associated completion routine are shown in Figure 2. When called by the FORTRAN program, TRIGER monitors both Schmitt triggers until one of them detects a tone. Whenever the input signal from one channel of the tape recorder exceeds the threshold for the corresponding Schmitt trigger, a status bit is set that is detected by TRIGER. Thus, TRIGER can determine the frequency of a tone by counting the number of times the threshold is exceeded in a fixed interval. Once a tone has been detected, TRIGER counts the number of peaks that occur in the first $100 \mathrm{msec}$ of the tone. When the tone ends, TRIGER provides the frequency count and the channel number to the FORTRAN program.

As written, the MACRO routine works only with the clock in the Lab Peripheral System. However, the modifications required to adapt this routine to currently available clocks are trivial. The old and new clocks are functionally equivalent, but the status bits have been rearranged.

A program written in FORTRAN IV controls the analysis of the tones. As shown in Figure 3, the program calls TRIGER to obtain a frequency count and channel number for each response. The frequency count is compared with the known tone frequencies to determine the corresponding response. Each experimental task

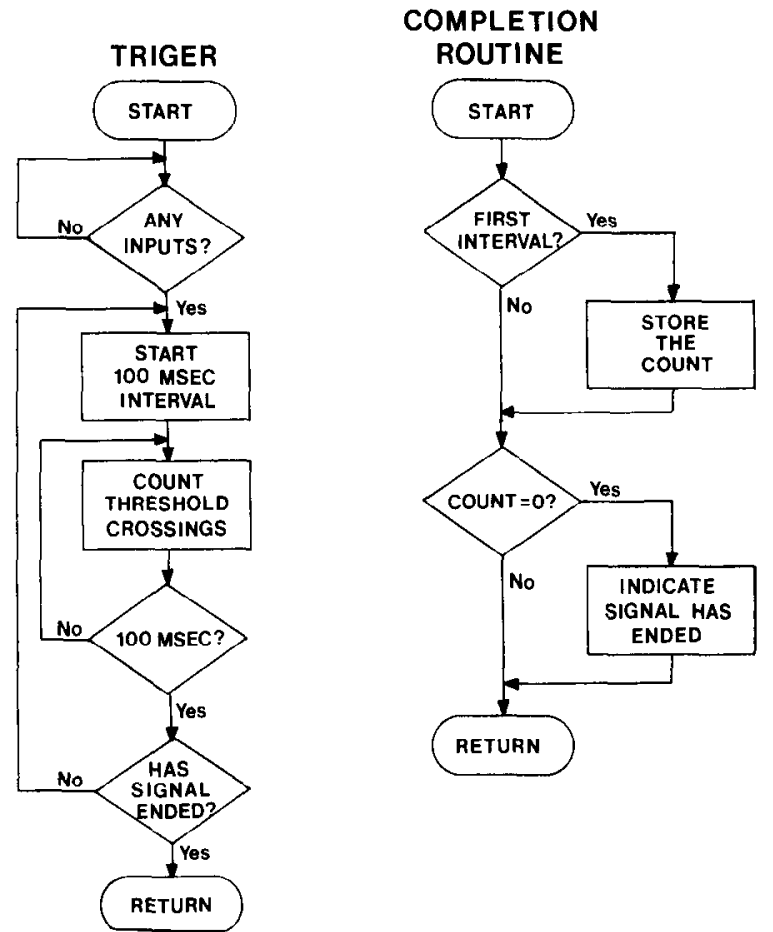

Figure 2. Flowcharts of MACRO routines to detect a tone and count its frequency.

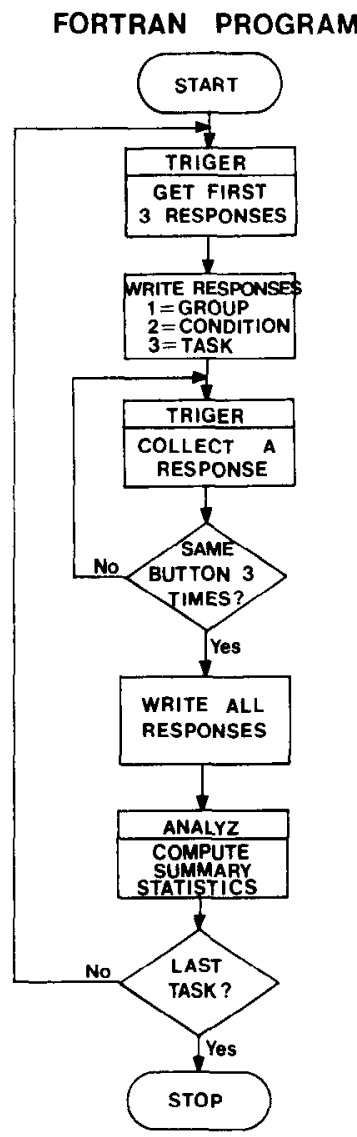

Figure 3. Flowchart of FORTRAN program to control the analysis of the communication-box data. 
begins and ends with a prearranged sequence of responses that also defines the experimental conditions. At the end of each task, the series of responses and time of occurrence of each response are written in a disk file. An analysis routine provides summary statistics of each subject's ratings. Currently, the analysis routine only computes mean ratings; however, additional analyses may be performed on the decoded data in the disk file.

To provide a concrete example of the data output and how the data are used, we return to the research problem summarized earlier. The research question concerns the correlation between couples' ratings of each other's interaction and their current relationship satisfaction. Figure 4 summarizes the output for one of our couples on an interaction task (i.e., the Inventory of Marital Conflicts, IMC; Olson \& Ryder, 1970) that presents a hypothetical marital conflict and asks couples

COUPLE 11 EXPERIMENTAL PREASS 1 IMC $1 \& 2$

\begin{tabular}{|c|c|c|}
\hline $\begin{array}{r}5 \\
13\end{array}$ & 1 & 1 \\
\hline-4 & 59 & \\
\hline 3 & 107 & \\
\hline-4 & 154 & \\
\hline 3 & 211 & \\
\hline-2 & 265 & \\
\hline 4 & 295 & \\
\hline-4 & 370 & \\
\hline 4 & 389 & \\
\hline-5 & 408 & \\
\hline 3 & 426 & \\
\hline-5 & 449 & \\
\hline 4 & 479 & \\
\hline-5 & 493 & \\
\hline 3.500 & 4.143 & 3.846 \\
\hline $\begin{array}{l}5 \\
15\end{array}$ & 1 & 2 \\
\hline 5 & 21 & \\
\hline-4 & 35 & \\
\hline 5 & 89 & \\
\hline-4 & 126 & \\
\hline 4 & 155 & \\
\hline-4 & 191 & \\
\hline 4 & 204 & \\
\hline-3 & 219 & \\
\hline 3 & 228 & \\
\hline-3 & 291 & \\
\hline 4 & 302 & \\
\hline-2 & 332 & \\
\hline 4 & 362 & \\
\hline-4 & 400 & \\
\hline 3 & 424 & \\
\hline 4.000 & 3.429 & 3.733 \\
\hline
\end{tabular}

Figure 4. Data output for one couple on two interaction tasks (IMCs 1 and 2). The output shows identifying information, number of ratings (e.g., 13, 15), who rated (female ratings designated by "-"), the rating (i.e., a number between 1 and 5), the time of rating in seconds (e.g., 59, 109), and means for male, female, and couple, for each task. to resolve the situation. The mean communication-box ratings, shown in Figure 4 for each IMC task, are then correlated with the individual's relationship satisfaction. The results of a recent study (Markman, Jamieson, \& Floyd, in press) indicate a significant positive correlation between communication-box ratings and relationship satisfaction $(r=.36, p<.01)$. We also have a computer program that provides analyses of the sequential dependencies in the couples' interaction, based on their ratings (Bakeman \& Dabbs, 1976; Gottman, Markman, \& Notarius, 1977). For example, we can determine the conditional probability of a husband's rating his wife positively given that the wife rated the previous set of his statements positively. This enables tests of constructs such as reciprocity and dependency in marital and family relationships (Gottman, 1979).

\section{APPLICATIONS}

In its current form or with minor modifications, this system can be applied to a variety of research problems in addition to self-observations of couples: (1) The system can be used in any self-observation situation in which researchers are interested in subjects' reactions to their own behavior or the behavior of other interactants (e.g., in a study of group interaction). (2) Couples can use the system to rate the intent of, as well as the reaction to, their communications (e.g., Gottman et al., 1976). (3) Couples can watch videotapes of their own or other couples' interaction and rate behaviors on dimensions of theoretical interest (e.g., Floyd, Note 1). (4) Objective coders can use the system, which is significantly less expensive (e.g., $\$ 50$ plus tape player) than most currently available altematives. Since most observational researchers reduce their codes to three to eight summary codes (Markman et al., 1981), only minor modifications in the system would be necessary. (5) The two channels can be used to independently code verbal and nonverbal components of communication, which should increase the discriminative validity of observational systems (Gottman et al., 1977). (6) Finally, the system can be made portable with minor changes (e.g., using a smaller and lighter stereo cassette player, such as a Sony Walkman) and thus can be used in home, school, or other relevant settings.

\section{SUMMARY}

We have described a computerized audio cassette system that allows for the recording, storage, and analysis of self-observational data. The data are prepared for lag-sequential analysis (Bakeman \& Dabbs, 1976), which is becoming the recommended procedure for analyzing observational data with populations ranging from thesus monkeys (Altmann, 1965) to infants (Sackett, 1980) to parents (Gottman et al., 1977). Finally, the system is small enough to be held easily in 
the hand, and it is inexpensive and applicable to a wide variety of research problems in the areas of social and applied clinical psychology. These areas have lagged behind others in psychology in the application of computer technology to solve research problems. However, the study of social interaction can be facilitated by use of such methods.

\section{REFERENCE NOTE}

1. Floyd, F. Insiders' and outsiders' perspectives of the communications of distressed and nondistressed married couples. Unpublished master's thesis, Bowling Green State University, Bowling Green, Ohio, 1980.

\section{REFERENCES}

Altmann, S. A. Sociobiology of rhesus monkeys. II: Stochastics of social communication. Journal of Theoretical Biology, $1965,8,490-522$.

Bakeman, R., \& DabBs, J. M., JR. Social interaction observed: Some approaches to the analysis of behavior streams. Personality and Social Psychology Bulletin, 1976, 2, 335-345.

Birchler, G., \& Spinks, S. Behavioral-systems marital and family therapy: Integration and clinical application. American Journal of Family Therapy, 1980, 8, 6-28.

Birchler, G. R., Weiss, R. L., \& Vincent, J. P. Multimethod analysis of social reinforcement exchange between maritally distressed and nondistressed spouse and stranger dyads. Journal of Personality and Social Psychology, 1975, 31, 349-360.

GotTman, J. Empirical investigations of marriage. New York: Academic Press, 1979.

Gottman, J., Markman, H., \& Notarius, C. The topography of marital conflict: A study of verbal and nonverbal behavior. Journal of Marriage and the Family, 1977, 39, 461-477.

Gottman, J., Notarius, C., Markman, H., Bank, S., Yoppi, B., \& RuBin, M. E. Behavior exchange theory and marital decision making. Journal of Personality and Social Psychology, 1976, 34, 14-23.

Markman, H. J. The application of a behavioral model of marriage in predicting relationship satisfaction of couples planning marriage. Journal of Consulting and Clinical Psychology, $1979,4,743-749$.

Markman, H., \& Floyd, F. Possibilities for the prevention of marital discord: A behavioral perspective. American Journal of Family Therapy, 1980, 8, 24-48.

Markman, H. J., Floyd, F., \& Dickson-Markman, F. Toward a model for the prediction and primary prevention of marital and family distress and dissolution. In S. Duck (Ed.), Personal relationships 4: Dissolving personal relationships. London: Academic Press, in press.

Markman, H. J., Jamieson, K., \& Floyd, F. The assessment and modification of premarital relationships: Preliminary findings on the etiology and prevention of marital and family distress. In J. Vincent (Ed.), Advances in family interventions, assessment and theory (Vol. 3). Greenwich, Conn: JAI Press, in press.

Markman, H. J., Notarius, C., Stephen, T., \& Smith, R. Behavioral observation systems for couples: The current status. In E. Filsinger \& R. Lewis (Eds.), Observing marriage: New behavioral approaches. Beverly Hills, Calif: Sage Publications, 1981.

OLson, D. Insiders' and outsiders' view of relationships: Research strategies. In G. Levinger \& H. L. Raush (Eds.), Close relationships. Amherst: University of Massachusetts Press, 1978.

OLson, D. H., \& RYDER, D. G. Inventory of marital conflicts (IMC): An experimental interaction procedure. Journal of Marriage and the Family, 1970, 32, 443-448.

Raush, H. L., Barry, W. A., Hertel, R. K., \& Swain, M. A. Communication, conflict and marriage. San Francisco: Jossey-Bass, 1974.

Sacketr, G. P. The lag sequential analysis of contingency and cyclicity in behavioral interaction research. In J. D. Osofsky (Ed.), Handbook of infant development. New York: Wiley, 1980.

Sidowski, J. B. (Ed.). Behavior research methods \& instrumentation (Vol. 9). Austin, Tex: Psychonomic Society, 1977.

Smith, E. O., \& Begeman, M. L. BORES: Behavior observation recording and editing system. Behavior Research Methods \& Instrumentation, 1980, 12, 1-7.

Stephenson, G. R., \& Roberts, T. W. The SSR system 7: A general encoding system with computerized transcription. Behavior Research Methods \& Instrumentation, 1977, 9, 434-441.

Thibaut, J. W., \& Kelley, H. H. The social psychology of groups. New York: Wiley, 1959.

Torgerson, L. Datamyte 900 . Behavior Research Methods \& Instrumentation, 1977, 9, 405-406.

WEISS, R. Strategic behavioral marital therapy: Toward a model for assessment and intervention. In J. Vincent (Ed.), Advances in family intervention, assessment and theory (Vol. 1). Greenwich, Conn: JAI Press, 1980.

Weiss, R. L., Hops, H., \& Patterson, G. R. A framework for conceptualizing marital conflict: A technique for altering it, some data for evaluating it. In L. A. Hamerlynck, L. C. Handy, \& E. J. Mash (Eds.), Behavior change: The Fourth Banff Conference on Behavior Modification. Champaign, Ill: Research Press, 1973. 